\title{
POSTRAUMATIC STRESS DISORDER IN KARACHITES DUE TO RANDOM EVENTS OF VIOLENCE.
}

\author{
Sadaf Ahmed $^{1 \& 2}$, Shamoon Noushad ${ }^{1}$, Sehrish Shahzad ${ }^{1}$, Syed Zain Azher', Adnan Aziz ${ }^{1}$ \& Muhammad Taha Saleem ${ }^{1}$ \\ 1. Advance Educational Institute \& Research Centre (AEIRC) \\ 2. Department of Physiology, University of Karachi. \\ Corresponding Author Email: shamoon@aeirc-edu.com
}

\begin{abstract}
Karachi is one of the biggest City in Asia and since past 20 years terrorism in Karachi is increasing frequently, due to these terrorist activities people living here have developed several phobias and anxiety disorders. To contrast the occurrence of traumatic events and its relationship with symptoms of post-traumatic stress disorder in Karachites. Survey of residents of Karachi was conducted between January 12, 2011 and March 4, 2012. Symptoms of PTSD were assessed using questionnaire related to psycho social factors that prone to PTSD .Out of total 164 both male and females, $62 \%$ of respondents reported appetite changes due to these terrifying activities, $58 \%$ of respondents reported hostile personalities , depression \& mood fluctuations, while remaining 30\% reported insomnia. 76.82\% reported depression According to their economical condition $71 \%$ Middle class was highly affected as compare to upper class and lower class. There was also a significant difference observed among the populations who are engaged both in education and also doing jobs for survivals. $88 \%$ of them were found frustrated \& protesting against the situation of the city. The results of the current study suggest that the trauma incident by the resident population is significant. Stresses tend to be numerous and chronic. The trauma experienced correlated strongly with psycho social, somatic, PTSD symptoms and depression.
\end{abstract}

\section{KEYWORDS}

Postraumatic Stress, Violence, Karachi, Stress, Sadaf Stress Scale, psychosocial

\section{INTRODUCTION}

Karachi has faced recurrent violent attacks during the last years, which have claimed hundreds of lives. According to data collected from different sources, during the last eight years 11,990 civilians lost their lives due to fatal attacks and bomb blasts in city. Different types of violence like target killing, sectarianism and terrorism engulf lives of 5,549 people from 2003 through 2011. Out of which, 1600 have targeted killed in the year 2011(Mohammad, 2012).Persistent increase in violent events in Karachi can be a major cause in developing PTSD and related symptoms in our population. Post-traumatic stress disorder is an anxiety disorder which an ability of any individual for impaired functioning after emotional reactions to memories of any distressing event (Yehuda, 2000). This condition is characterized by disturbing events like nightmares, flashbacks and invasive thoughts (Van Etten,1998). It occurs after experiencing traumatic stress in situations like natural disasters, accidents, violence, rape and other stressable events (Yehuda, 2002). Most of the existing research on PTSD has focused in those individuals who have been present at the site of attack (Shalev, 1992).The National Co morbidity Survey found that about $80 \%$ of patients with PTSD meet the criteria for at least one other psychiatric disorder. Symptoms of PTSD and depression overlap significantly. Persistent hyper arousal in PTSD suggest autonomic dysregulation, associated with elevated heart rate and several other pathological conditions (Blechert, 2007). However, there is less research on a consequence of mass violence or persistent fear of terrorism on those individuals who were affected indirectly (Blechert, 1992). According to some researches, indirect exposure includes viewing or listening news of violent events and effects of media coverage on mind (Schlenger, 2002; Smoller, 2000). Most of the previous literature investigating such mechanisms focused on high-risk samples of people exposed to circumscribed traumatic exposures or traumatic events (e.g. war, disasters, accidents, rape) (Nutt,
2000) but there is a little research so far has been done to prevent and treat PTSD, although the condition has high profile (Yum, et al. 2006).Persons that exposed to trauma not all necessarily develop PTSD.PTSD represents failure to maintain physiological homeostasis (Yum, 2006).Failure of homeostasis leads to stress, the nervous and endocrine system that leads to the effect of target sites such as sleep-wake cycle, fear-reward system, reproductive system, cardiac, respiratory, immune and metabolic systems(George, 2009). These disturbance in internal body systems, externally appears in form of different behaviors like sleep disorders, mood liabilities, changes in thinking pattern. Such effects amongst the Karachities have yet to be studied. It was necessary that the incidence of these symptoms and the effect on their personal as well as social lifestyle be studied. This will assist to conclude the occurrence and severity of terrorism-related anxiety. Post traumatic effects may include aggression, fear, hostile personality, insomnia emotional instability; even avoid discussing about their casts and ethnicity. According to study conducted by Maurice, the rate of PTSD was higher in women (2.6\%) than for men (0.9\%) (Jakupcak, 2007).

\section{METHODOLOGY}

Survey of residents of Karachi was conducted during traumatic events between January 12, 2011 and March 4, 2012. Randomly 164 people were selected in which 95 people are female and 69 are male. This paper is draw to contrast the occurrence of traumatic events and its relationship with symptoms of post-traumatic stress disorder. Symptoms of PTSD were assessed by using questionnaire related to psycho social factors that prone to PTSD. We also discuss the depression level. 


\section{RESULT}

The data presented in this survey was based on the questions; in our survey, $57.92 \%$ respondents were females. Few symptoms observed higher in females than males like appetite changes, tiredness. Economically, $79.87 \%$ belongs to middle class $89.02 \%$ were un-married we observe different symptoms in Karachite, due to traumatic events $62.19 \%$ individuals reported their changes in appetite Out of which $70.03 \%$ were females. . $60.36 \%$ felt tiredness $56.7 \%$ have difficulty in maintaining sleep 70\% of PTSD subjects suffered sleep disturbances. Depression observed in $76.82 \%$ respondents Out of which $65.78 \%$ were males. $70.12 \%$ had irritability $51.21 \%$ people hypersensitive to small noise, people and tremors $52.43 \%$ respondents avoid places, peoples and topics related to traumatic event $21.95 \%$ used medicines, $7.92 \%$ smoking and $1.82 \%$ were drug abused during traumatic situations in the city $54.26 \%$ think about the event when they do not want to $54.26 \%$ felt trouble in enjoying events that they were used to $70.12 \%$ got upset when something reminds about the event $53.65 \%$ people made effort/difficult to forget the $34.75 \%$ peoples thought protesting against events, $2.43 \%$ had suicidal thoughts Table 1.Peak age group that suffered more or showed more symptoms is 21-30 yrs. Mostly PTSD symptoms were found in Students.

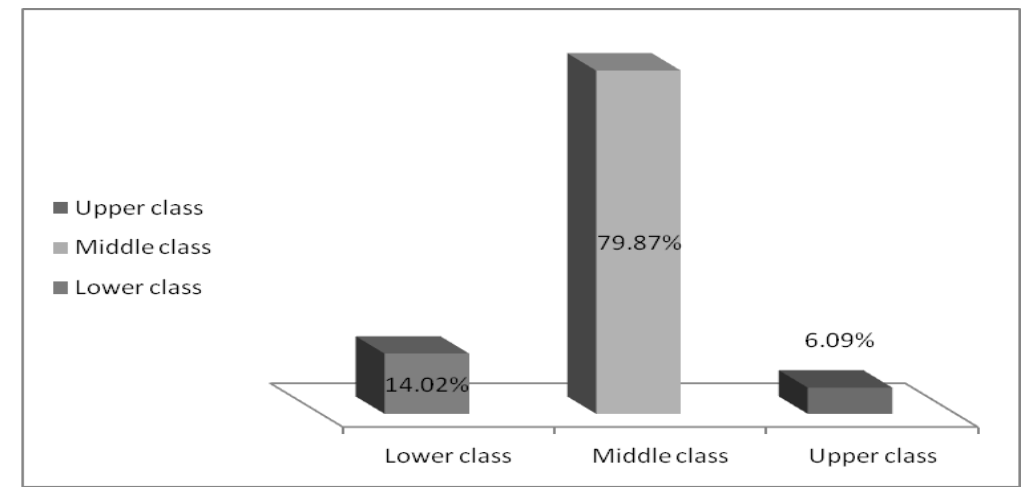

Figure 1: The figure shows $6.09 \%$ peoples belong to upper class while $79.87 \%$ peoples belong to middle class and $14.02 \%$ peoples belongs to lower class.

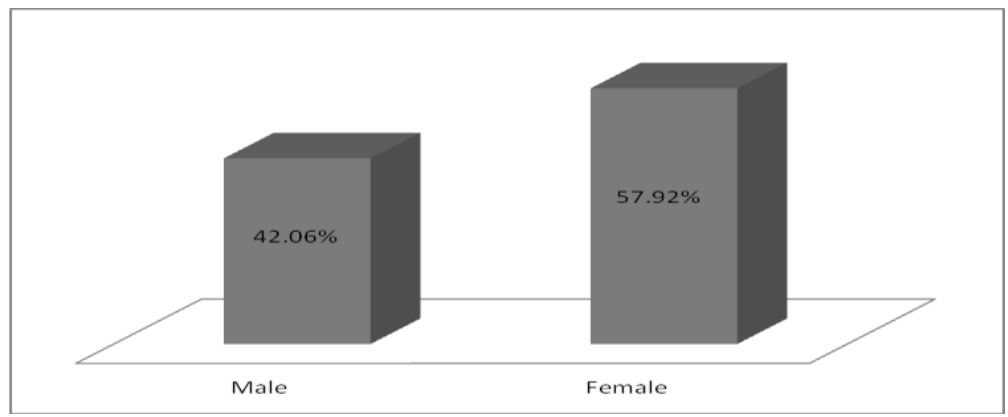

Figure 2: The figure shows $\mathbf{4 0 . 0 6 \%}$ peoples are males while $\mathbf{5 7 . 9 2 \%}$ peoples are females and $\mathbf{1 . 8 2} \%$.

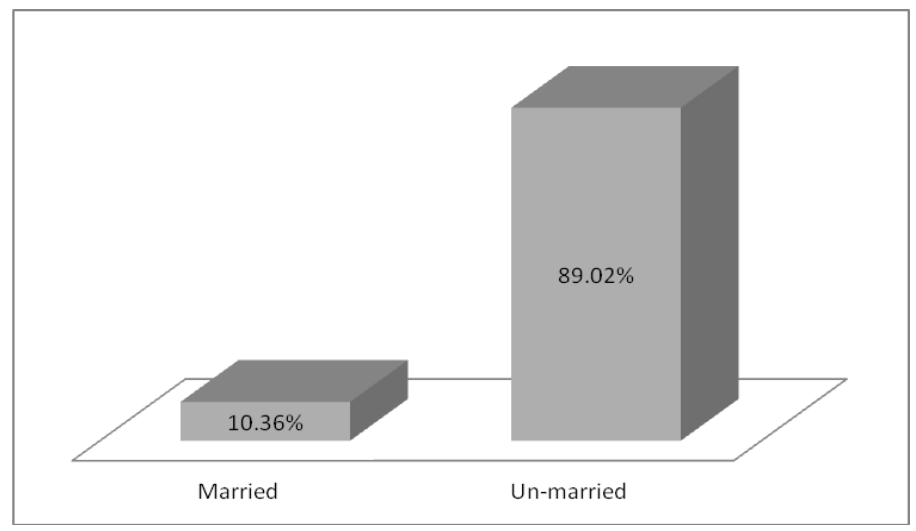

Figure 3: The figure shows $10.36 \%$ peoples are married and $89.02 \%$ are un-married. 
Table: reporting symptoms of PTSD by affecters, when they were inquired about following feeling.

$\begin{array}{cc}\text { Appetite } & 62.19 \% \\ \text { Tiredness } & 60.36 \% \\ \text { Nightmares } & 43.90 \% \\ \text { Sleep disturbances } & 56.70 \% \\ \text { Nightmares } & 43.90 \% \\ \text { Depressed } & 76.82 \% \\ \text { Irritability } & 70.12 \% \\ \text { Oversensitivity } & 51.21 \% \\ \text { Avoid places, people, topics } & 52.43 \% \\ \text { Unwanted memories } & 54.26 \% \\ \text { Trouble enjoying } & 54.26 \% \\ \text { Sadness due to memory } & 70.12 \% \\ \text { Self forcing forget } & 53.65 \% \\ \text { Medication } & 3.04 \% \\ \text { Drug abuse } & 21.95 \% \\ \text { Insurance } & 1.82 \%\end{array}$

\section{DISCUSSION}

The 'apparent killings' and bomb blasts has brought our attention to a grave issue that is bringing our populace in post-traumatic stress condition. In response to the rising incidence rates of non peaceful and surprising terror activities like snatching of valuables and gun shots these situations have serious attempts to impact mental health. This have induced burned out feelings and sufferings from high levels of fatigue with category of clinically distressed; a level which is considered to affect the lives of individuals both at work and at home. Various reasons are cited for stressing out, most prominently media aggravating the fear of such happenings and self exposure to such event (Israr, 2012) Being a bona fide Karachite, frustration and depression is usual as in this city where people never seemed be safe the chaos insists that you keep reinventing psychological disturbances and in such anarchy a developed false sense of being is driving the populace to madness, resentment and humiliation. Even normal routines like going out to office, school or other can drive and trigger behavioral aspects showing some degree of PTSD. The target killing of 10 to 15 people in the troubled Karachi city in a single day has become so common that now many do not fully notice. The killing of over one dozen innocent people in the city is no more considered a 'big issue' by those who are in controlling authorities. Though this unabated violence, including targeted killings, arson, robbery, street crime etc, there is no realization of the severity but the implication of the killings in the power corridors social and psychological cost of violence is immeasurable (Shahina, 2012) Origin of PTSD is exposure to a traumatic event such as physical or sexual abuse, violence, combat, natural disaster, or accident. People with other psychiatric disorders are more likely to develop PTSD after a traumatic event and it appears to be related to a combination of genetic predisposition and environmental factors. The early reaction of fear is inherently biologic, but it can be influenced by the person's subjective interpretation of the event, which in turn is influenced by the person's previous experiences and other risk factors. The psychological and biologic response to a traumatic event is determined by the characteristics of both the event and the person concerned (Yehuda, 2002) Comparative study between sleep disturbance in PTSD group and insomnia in nonPTSD group, PTSD group reported more anxiety during waking hours and more fatigue during daytime than the non-PTSD insomnia group (Inam, 1990).Sleep talking, sleep paralysis and injurious behavior during sleep were reported by PTSD individuals (Ohayon, 2000). Frequent sleep disorder suffered by Karachite population was insomnia. The most common symptom of PTSD is insomnia (DeViva, 2005). Nightmares of PTSD group were more repetitive and more disrupting to maintain sleep than the nonPTSD insomnia group (Inam, 1990). Our study showed 56.09\% did not have nightmares Matthew conducted study among Iraq and Afghanistan War veterans who were positive for PTSD had greater anger and hostility than those in the non-PTSD groups (Jakupcak, 2007).The results of this study show that traumatic events can be associated with the early and simultaneous development of both PTSD and major depression or a combination .The intensity of depressive symptoms in PTSD resembles that of major depression. These results one should be aware of the study's limitations, which include a comparatively short follow-up period or experience of single and short traumatic events and other traumatic circumstances. Psychiatrists say the number of people suffering from psychological disorders, including depression, anxiety and stress, is increasing at alarming rate in the city. They say continuing violence and its over-projection by the media, especially the electronic media, have a detrimental effect on the psychological health of Karachite. The number of people suffering from depression and different metal illnesses is growing with each passing day. There has been a marked increase in the influx of mental diseases and depression patients at the OPDs of different 
public and private hospitals of the city (Shahina, 2012).The inventory of human requirements includes the physical security, safety, community connection and aesthetic approval but the continuous violence has sense of physical insecurity among People and they are worried about getting their daily meal and are unable to fulfill even their basic needs. The worsening law and order situation and unabated violence have robbed them of their sense of security and safety, due to which a large number of people of the country especially Karachi have become prone to psychological disorders.

\section{REFERENCES}

- Blechert, J., Michael, T., Grossman, P., Lajtman, M., \& Wilhelm, F. H. (2007). Autonomic and respiratory characteristics of posttraumatic stress disorder and panic disorder. Psychosomatic Medicine, 69(9), 935-943.

- DeViva, J. C., Zayfert, C., Pigeon, W. R., \&Mellman, T. A. (2005). Treatment of residual insomnia after CBT for PTSD: Case studies. Journal of Traumatic Stress, 18(2), 155-159.

- Ferrada-Noli, M., Asberg, M., Ormstad, K., Lundin, T., \&Sundbom, E. (1998). Suicidal behavior after severe trauma. Part 1: PTSD diagnoses, psychiatric comorbidity, and assessments of suicidal behavior. Journal of Traumatic Stress,11(1), 103-112.

- George, P. (2009). Chrousos. Nature Reviews Endocrinology, (5), 374-381 doi:10.1038/nrendo.2009.106

- Inman, D. J., Silver, S. M., \& Doghramji, K. (1990). Sleep disturbance in post-traumatic stress disorder: a comparison with non-PTSD insomnia. Journal of Traumatic Stress, 3(3), 429437.

- Israr , A.(2012). Psychological, social cost of violence Copyright Business Recorder. Retrieved from http://www.brecorder.com/weekend

magazine/654:/1193631:psychological-social-cost-ofviolence/?date $=2012-05-26$

- Jakupcak, M., Conybeare, D., Phelps, L., Hunt, S., Holmes, H. A., Felker, B.,\&McFall, M. E. (2007). Anger, hostility, and aggression among Iraq and Afghanistan war veterans reporting PTSD and sub threshold PTSD. Journal of traumatic stress,20(6), 945-954.
- Mohammad, N. (2012).Karachi: The State of Crimes,' the report below was commissioned by the Center for Research \& Security Studies. Retrieved from http://www.viewpointonline.net/component/content/article?id=1 835:2003-2011-karachi-violence-claimed-5549-lives-sp-18370

- Nutt, D. J. (2000). The psychobiology of posttraumatic stress disorder. Journal of Clinical Psychiatry.

- Ohayon, M. M., \& Shapiro, C. M. (2000). Sleep disturbances and psychiatric disorders associated with posttraumatic stress disorder in the general population. Comprehensive psychiatry, 41(6), 469-478.

- Schlenger, W. E., Caddell, J. M., Ebert, L., Jordan, B. K., Rourke, K. M., Wilson, D., \&Kulka, R. A. (2002). Psychological reactions to terrorist attacks: findings from the National Study of Americans' Reactions to September 11. Jama, 288(5), 581-588.

- Shahina, M.(2012). Pakistanis predisposed to post-traumatic stress, The News International. Retrieved from http://www.thenews.com.pk/Todays-News-6-113689-

Pakistanis-predisposed-to-post-traumatic-stress

- Shalev, A. Y. (1992). Posttraumatic stress disorder among injured survivors of a terrorist attack: predictive value of early intrusion and avoidance symptoms. The Journal of nervous and mental disease, 180(8), 505-509.

- Smoller, B., \&Sokol, J. (2000). Post-traumatic stress disorder in the age of terror. Maryland medicine: MM: a publication of MEDCHI, the Maryland State Medical Society, 2(4), 39-43.

- Van Etten, M. L., \& Taylor, S. (1998). Comparative efficacy of treatments for post-traumatic stress disorder: a meta-analysis.

- Yehuda, R. (2000). Post-Traumatic Stress Disorder. Encyclopedia of Cognitive Science.

- Yehuda, R. (2002). Post-traumatic stress disorder. New England Journal of Medicine, 346(2), 108-114.

- Yum, B. S., Roh, J. H., Ryu, J. C., Won, J. U., Kim, C. N., Lee, J. E., \& Kim, K. Y. (2006). Symptoms of PTSD according to individual and work environment characteristics of Korean railroad drivers with experience of person-under-train accidents. Journal of psychosomatic research, 61(5), 691-697. 